\title{
Dark Triad and Social Media Addiction among Undergraduates: Coping Strategy as a Mediator
}

\author{
Poh Chua Siah \\ Universiti Tunku Abdul Rahman, Kampar Campus, Malaysia \\ ORCID: 0000-0003-0991-1313 \\ Jie Yeng Hue \\ Universiti Tunku Abdul Rahman, Kampar Campus, Malaysia \\ ORCID: 0000-0001-7848-7822 \\ Bernie Zi Ru Wong \\ Universiti Tunku Abdul Rahman, Kampar Campus, Malaysia \\ ORCID: 0000-0002-7318-6542 \\ Sin Jie Goh \\ Universiti Tunku Abdul Rahman, Kampar Campus, Malaysia \\ ORCID: 0000-0003-1855-1567
}

Received: 13 Dec 2020

Accepted: 19 May 2021

\begin{abstract}
The excessive use of social media is prevalent among undergraduates. Dark triad personality is one of the significant predictors of social media addiction, but inconsistent findings were reported. This study adopted the personality-coping-outcome theory as a framework to examine whether coping strategies mediate the effects of dark triad personality on social media addiction. The purposive sampling method was used to recruit 219 undergraduates for a survey. The results showed that only narcissism is associated with social media addiction, and only avoidance coping strategy mediated the effects of pathology on social media addiction. It is suggested a complete theory is required to explain the relationships between dark triad personality and social media addiction, and a coping scale to be developed to cover the coping strategies that fit dark triad personality.
\end{abstract}

Keywords: social media addiction, Dark Triad, coping strategies, Machiavellianism, narcissism, pathology

\section{INTRODUCTION}

Social media channels on the Internet, allowing users to share with others online with Facebook, Whatsapp, Youtube, or Instagram (Carr \& Hayes, 2015). Through social media, people can create profiles and access various platforms and devices to engage in multiple social activities such as file sharing, chatting, and online gaming (Bányai et al., 2017). The Malaysian Communications and Multimedia Commission (2018) reported that Internet users' most common activities were visiting social networking platforms. The two most popular communication and social networking platforms were WhatsApp and Facebook.

Studies found that social media addiction was prevalent among generation Z (1991 and after), as technology advancement emerged when they were born (PrakashYadav \& Rai, 2017). Social media addiction is defined as an uncontrollable motivation to be involved in social media activities. It drives the individual to feel a need 
to engage in social media for a sense of satisfaction regardless of the time and effort spent (Schou Andreassen \& Pallesen, 2014). People addicted to social media frequently feel the need to regularly check their social media accounts to avoid seclusion (Afacan \& Ozbek, 2019). They cannot control their urge to log in to their social media accounts to feel satisfaction (Hou et al., 2019).

The high social media addiction among undergraduates can be because this generation is equipped with better literacy skills than other generations. They might be more vulnerable to being addicted to social media and thus affect their academic studies (Afacan \& Ozbek, 2019). Thatcher et al. (2008) suggested that undergraduates are more likely to be attracted by pleasurable experiences brought by social media, such as playing games and watching videos. Reinecke et al. (2018) also claimed that as the Internet offers users high autonomy, opportunities for identity exploration, and a space free of parental control, undergraduates may find that the Internet is highly appealing and become addicted to social media.

Mamun and Griffiths (2019) conducted a study in Hungarian, and they found that out of six thousand teenagers, four percent of teenagers were addicted to social media. However, Mahamid and Berte (2019) surveyed 744 Palestine university students and found that about seventy-four percent were addicted to social media. Malaysian Communications and Multimedia Commission (2018) also reported that about seventy percent of social media users are college or undergraduate students among full-time students.

Negative outcomes of social media addiction have been reported. Hawi and Samaha (2017) reported that individuals with a higher social media addiction level also have lower self-esteem. In Malaysia, social media's over-usage is related to poor 'students' academic performance, negative interpersonal skills, threatening real-life relationships, and reducing self-esteem (Sriwilai \& Charoensukmongkol, 2016).

Due to the high prevalence of social media addiction among the younger generation (Al Mamun \& Griffiths, 2019; Hawi \& Samaha, 2017), it is vital to find out the relevant factors to social media addiction among the younger generation. Accordingly, this study targeted the factors associated with social media addiction among undergraduate students.

One of the factors associated with social media addiction is personality (Demircioğlu \& Köse, 2018), such as the dark triad personality (Book et al., 2015; Paulhus \& Williams, 2002). Chung et al. (2019) claimed that dark triad personality is potentially considered a crucial particular difference factor that plays a role in developing and conserving addictive actions. The Dark Triad consists of three distinctive and maladjusted personality traits: Psychopathy, narcissism, and Machiavellianism (Malesza \& Ostaszewski, 2016).

Narcissism is related to a person's positive beliefs regarding being conceited, entitled, grandiose and manipulative (Hyatt et al., 2018). Machiavellianism is characterized as manipulative and cynical, where people who possess this personality may be regarded as cold and selfish (Ináncsi et al., 2016). Psychopathy is a personality that is seen negatively as psychopathic people are known to be lacking the ability to feel guilt or empathy (Hare, 1998).

Overall, these three traits are often described as low empathy and have a higher tendency to cheat and manipulate to achieve their goals. They are more likely to engage in ruthless exploitation to maximize their benefit when the perceived risk is low (Book et al., 2015). Besides, due to their lack of empathy, an underlying characteristic of dark triad personality is unsociable (Jonason \& Webster, 2012; Kircaburun et al., 2018).

Narcissism is relevant to social media addiction as social media can help narcissists conceal their wrong side by choosing what they wanted to share to boost their ego. Machiavellianism is relevant to social media addiction as social media provides an opportunity for Machiavellianism individuals to cheat or trick people easily online because the standard of morality is subjective. Psychopaths are also relevant to social media addiction. Social media is a widely preferred platform for them to displace their impulsive yet reckless attitudes where disciplinary actions are less likely to be taken than real-life (Demircioğlu \& Köse, 2018; Jonason \& Webster, 2012).

Nonetheless, studies found different associations between the three traits of dark triad personality with social media addiction. A survey of 118 Malaysian university students showed that only the psychopathy trait 
is positively associated with social media addiction (Chung et al., 2019). A study with 237 Turkey university students also showed that high in psychopathy tend to have a higher social media addiction (Demircioğlu \& Köse, 2018). However, a study with 181 Turkey University students found that both Machiavellianism and narcissists use social media excessively (Kircaburun et al., 2018).

These inconsistencies can be attributed to coping strategies. According to the personality-coping-outcome theory, the associations between personality and outcomes can be relevant to the coping strategies. The theory assumes that personality influences one's coping style differently when one encounters stressful situations, which further affects one's adjustment outcomes (Gallagher, 1996). Coping strategies are how individuals utilize their behaviors and cognitive abilities to regulate excessive demands that are not within their personal control (Folkman, 2013; Lazarus \& Folkman, 1987). According to Parker and Endler (1992), specific coping strategies can mitigate stress and facilitate positive psychological consequences, while others aggravate stress and facilitate negative psychological consequences. Therefore, Chou et al. (2015) suggested that poor coping skills will result in social media addiction that will deteriorate the individual's wellbeing.

Usually, coping methods are categorized into two types: Problem-based coping (strategies aimed at solving the problem or doing something to change the source of stress) and emotion-based coping (strategies aimed at reducing or managing feelings of distress associated with the stressor). However, the categories of two coping strategies have been argued to oversimplify the strategies adopted by people to deal with difficult situations (Skinner et al., 2003). Therefore, different ways to categorize coping strategies have been proposed. For example, Suls and Fletcher (1985) proposed approach versus avoidant coping categories, Benson (2010) proposed engagement, distraction, disengagement, and cognitive framing, and Baumstarck et al. (2017) proposed social support, problem-solving, avoidance, and positive thinking. In this study, we adopted the four coping strategies presented by Baumstarck et al. (2017) as social support is included as a coping strategy, which can be important among individuals with dark triad personalities who are deficient in social relationships (Jonason \& Webster, 2012; Kircaburun et al., 2018).

\section{Aims of the Study}

Using the personality-coping-outcome theory as a framework (Gallagher, 1996), this study examines the relationships among dark triad personality and social media addiction and whether coping strategies mediated the dark triad personality on social media addiction. The research questions and conceptual framework were as follows:

\section{Research questions}

RQ1: What are the relationships between Dark Triad personality and social media addiction?

RQ2: Is coping strategy a statistical mediator for Dark Triad personality's impact on social media addiction?

\section{Hypotheses}

H1: All three dark triad personalities (narcissism, Machiavellianism, and psychopathy) are positively associated with social media addiction.

H2: Coping strategy is a statistical mediator for Dark Triad personality's social media addiction effects. 


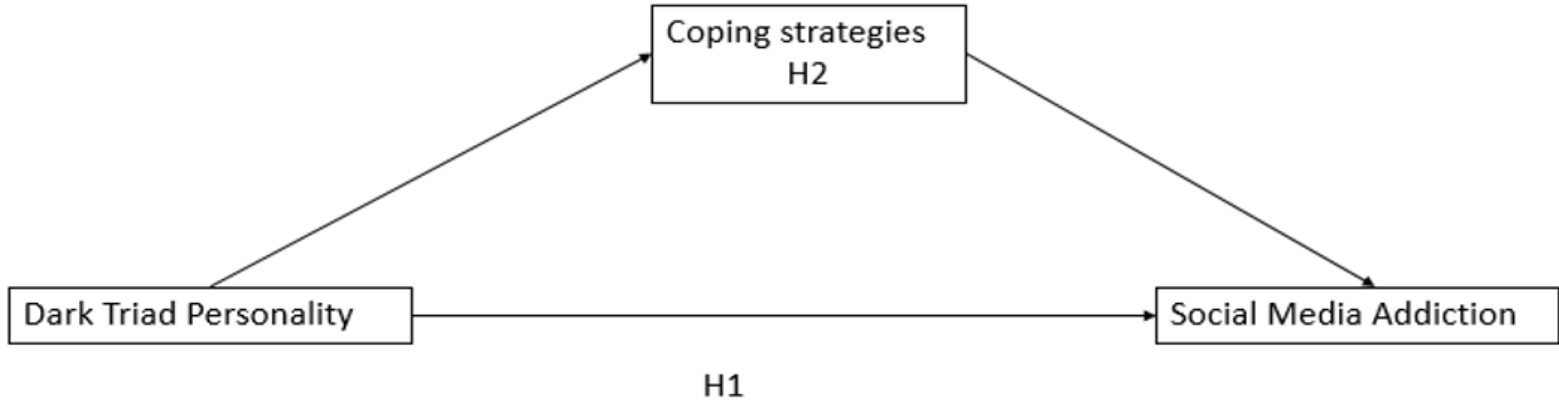

Figure 1. The conceptual framework

\section{METHODS}

\section{Design}

A cross-sectional survey design was used in this study. In this design, participants are recruited at one time to complete a survey (Shaughnessy et al., 2015).

\section{Participants}

Two hundred thirty participants were recruited from a university. Only 219 valid data were used for the analysis after excluding the incomplete questionnaire. The sample size of this study was larger than the estimated sample size of 55 , based on the $\mathrm{G}^{*}$ Power (effect size $=.15$, statistical power $=.8$, the probability $=$ .05 , predictors $=6$ ). About $42.5 \%$ of participants were males, and $57.5 \%$ were females. The sample's age range was 19 years old to 25 years old $(M=21.46, S D=1.17)$.

\section{Measurements}

Dark Triad Personalities. The Short Dark Triad 3 scale consists of 27 items (Jones \& Paulhus, 2014). There are three dimensions (narcissism, Machiavellianism, and psychopathy) on the scale, with nine items in each dimension. Participants were asked to answer from a five-point Likert scale ranging from 1 (Disagree strongly) to 5 (Agree strongly). A sample item of narcissism is "I know that I am special because everyone keeps telling me so." A sample item of Machiavellianism is "Most people can be manipulated and a sample item of psychopathy is "People often say I am out of control." The reported Cronbach alpha reliability for narcissism, Machiavellianism, and psychopathy were $.71, .77$, and .80 , respectively.

Coping Strategies. The Brief COPE was developed by Carver (1997). The scale consists of 28 items. Participants need to answer from a four-point Likert scale ( $1=$ "I haven't been doing this at all," 4 = "I've been doing this a lot"). There are four factors for the scale: Social support (8 items), problem-solving (4 items), avoidance (10 items), and positive thinking ( 6 items). Sample items of each factor are "I've been getting comfort and understanding from someone" (social support), "I've been taking action to try to make the situation better" (problem-solving), "I've been using alcohol or other drugs to help me get through it" (avoidance), and "I've been making jokes about it" (positive thinking). The Cronbach alpha of social support is reported as .82, .74 for problem-solving, .64 for avoidance, and .71 for positive thinking (Baumstarck et al., 2017).

Social Media Addiction. Social media addiction is measured through the Bergen Social Networking Addiction Scale (Andreassen et al., 2012). The scale consists of six items, and participants were asked to answer from a five-point Likert scale ( $1=$ "Very rarely", $5=$ "Very often"). A sample item from this scale includes How often during the last year have you felt an urge to use social media more and more?". The Cronbach alpha reliability of this scale is reported as .82 . 
Table 1. Construct Reliabilities of All Measurements

\begin{tabular}{lcccc}
\hline & Total items & $\begin{array}{c}\text { Number of items } \\
\text { removed }\end{array}$ & $\begin{array}{c}\text { Composite Reliability } \\
\text { (total items) }\end{array}$ & $\begin{array}{c}\text { Composite Reliability } \\
\text { (after item removed) }\end{array}$ \\
\hline Machiavellianism & 9 & 0 & .78 & .78 \\
Narcissism & 9 & 3 & .63 & .74 \\
Psychopathy & 9 & 0 & .71 & .71 \\
Avoidance & 10 & 1 & .78 & .78 \\
Positive thinking & 6 & 1 & .64 & .71 \\
Problem solving & 4 & 0 & .61 & .81 \\
Social Support & 8 & 2 & .83 & .70 \\
Social Media Addiction & 6 & 0 & .83 & .83 \\
\hline
\end{tabular}

Table 2. Discriminate Validities of All Measurements

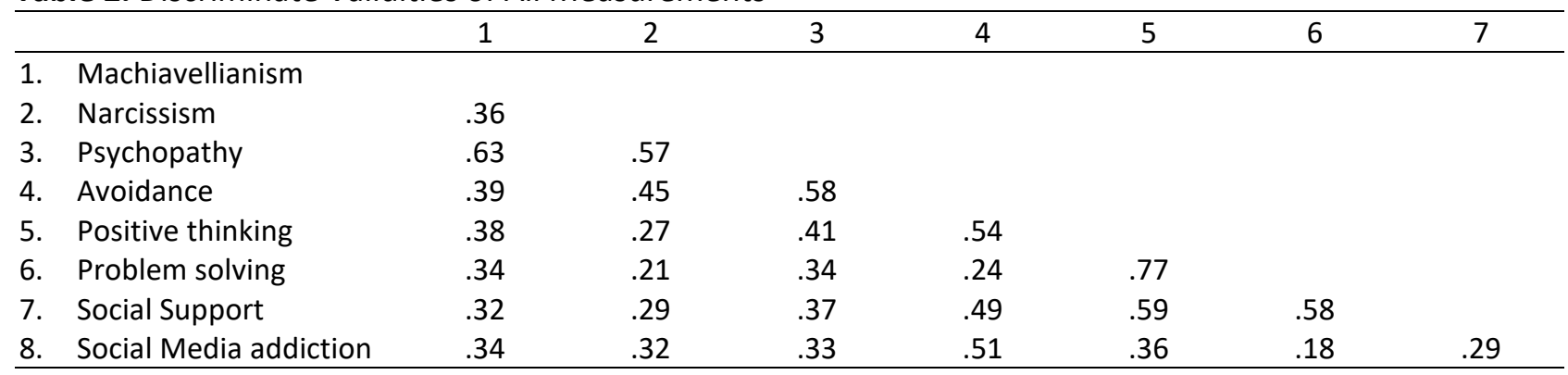

\section{Procedure}

After getting approval from the university's scientific and ethical committee, the purposive sampling method was used to select the participants that only undergraduate students were recruited. The participants were approached at different locations at a university. They were asked to answer a questionnaire. The first page of the questionnaire contained the informed consent form, and the second page is about their demographic information, such as age and gender. There are three scales in the questionnaire: The Short Dark Triads 3 scale, Brief COPE and the Bergen Social Networking Addiction Scale. No pilot study was conducted to examine the reliabilities of the measurements, as these measurements have been used in some projects that using the same population. Participants were asked to insert the questionnaire into an envelope, and researchers would come back to collect the sealed envelopes after 10 minutes. No pilot study was conducted to examine the reliabilities of the measurements, as these measurements have been used in some projects that using the same population.

\section{Data Analysis}

The data was typed and keyed in an excel file. The SPSS program was used for the descriptive statistics, and the SmartPLS program was used to examine the Partial Least Structural Equation Modeling.

\section{RESULTS}

\section{Measurement Model}

Construct Reliability. After removing some items in avoidance, positive thinking, social support, and Narcissism scales, the composite reliabilities are equal to or above the recommended values of .7 (Hair Jr et al., 2016). Correspondingly, the findings suggested that all measurements' latent constructs are acceptable (see Table 1).

Discriminant validity. The Heterotrait-Monotrait ratio was used to examine the discriminant validity of the measurements. As shown in Table 2, the measurements' discriminant validity is acceptable as the Heterotrait-Monotrait ratio of all results is below the critical values of .85 (Henseler et al., 2015). 
Table 3. Coefficient of Determination $\left(r^{2}\right)$, Effect Size $\left(f^{2}\right)$, And Collinearity Statistics (VIF) Of Measurements

\begin{tabular}{|c|c|c|c|c|}
\hline Dependent variables & Predictors & $\mathrm{R}^{2}$ & $f^{2}$ & VIF \\
\hline \multirow[t]{3}{*}{ Avoidance } & Machiavellianism & & .01 & 1.19 \\
\hline & Narcissism & .20 & .01 & 1.21 \\
\hline & Psychopathy & & .11 & 1.35 \\
\hline \multirow[t]{3}{*}{ Positive thinking } & Machiavellianism & & .03 & 1.19 \\
\hline & Narcissism & .11 & .01 & 1.21 \\
\hline & Psychopathy & & .03 & 1.35 \\
\hline \multirow[t]{3}{*}{ Problem solving } & Machiavellianism & & .06 & 1.19 \\
\hline & Narcissism & .06 & .01 & 1.21 \\
\hline & Psychopathy & & .02 & 1.35 \\
\hline \multirow[t]{3}{*}{ Social support } & Machiavellianism & & .02 & 1.19 \\
\hline & Narcissism & .08 & .01 & 1.21 \\
\hline & Psychopathy & & .03 & 1.35 \\
\hline \multirow[t]{7}{*}{ Social Media addiction } & Avoidance & & .05 & 1.48 \\
\hline & Positive thinking & & .01 & 1.34 \\
\hline & Problem-solving & & .01 & 1.27 \\
\hline & Social support & .23 & .03 & 1.32 \\
\hline & Machiavellianism & & .01 & 1.29 \\
\hline & Narcissism & & .03 & 1.25 \\
\hline & Psychopathy & & .01 & 1.56 \\
\hline
\end{tabular}

\section{Coefficient of Determination, Effect Size and Collinearity Statistics of Measurements}

The results of the analyses were shown in Table 3. As the variance inflation factor of all scales is also below 5 , no collinearity issue was found (Hadi et al., 2016). Besides, the results of $r^{2}$ reveal a medium effect size of the predictors on social media addiction, avoidance, and positive thinking coping strategies (Cohen, 1992). However, the results of $f^{2}$ indicate that each predictor has a small effect size on dependent variables (Hair Jr et al., 2016).

\section{Structural Model}

As shown in Table $\mathbf{4}$ and Figure 2, after controlling ages and gender, only narcissism is positively associated with social media addiction, $p=.034$. Only avoidance coping strategy is positively related to social media addiction, $p s<.05$. Machiavellianism adopted both positive thinking and problem-solving coping strategies, $p s<.05$. Psychopathy is found to be associated with avoidance coping strategy, $p=.001$. No association between narcissism and coping strategies was found $p s>.05$.

Table 4. Direct Effects of Predictors

\begin{tabular}{|c|c|c|c|c|}
\hline & Beta & Std Error & T value & P Values \\
\hline \multicolumn{5}{|l|}{ Social Media Addiction } \\
\hline Machiavellianism $\rightarrow$ Social Media addiction & .10 & .09 & 1.12 & .132 \\
\hline Narcissism $\rightarrow$ Social Media addiction & .17 & .09 & 1.83 & .034 \\
\hline Psychopathy $\rightarrow$ Social Media addiction & -.01 & .10 & .13 & .448 \\
\hline Positive thinking $\rightarrow$ Social Media addiction & .12 & .08 & 1.62 & .053 \\
\hline Problem-solving $\rightarrow$ Social Media addiction & -.05 & .08 & .60 & .274 \\
\hline Social support $\rightarrow$ Social Media addiction & .14 & .10 & 1.39 & .083 \\
\hline Avoidance $\rightarrow$ Social Media addiction & .25 & .08 & 3.10 & .001 \\
\hline \multicolumn{5}{|l|}{ Coping strategies } \\
\hline Machiavellianism $\rightarrow$ Problem solving & .26 & .10 & 2.71 & .004 \\
\hline Narcissism $\rightarrow$ Problem solving & .03 & .14 & .26 & .399 \\
\hline Psychopathy $\rightarrow$ Problem solving & -.16 & .17 & .94 & .173 \\
\hline Machiavellianism $\rightarrow$ Positive thinking & .19 & .09 & 2.09 & .019 \\
\hline Narcissism $\rightarrow$ Positive thinking & .03 & .11 & .26 & .398 \\
\hline Psychopathy $\rightarrow$ Positive thinking & .18 & .11 & 1.63 & .052 \\
\hline
\end{tabular}


Table 4 (continued). Direct Effects of Predictors

\begin{tabular}{lcccc}
\hline & Beta & Std Error & T value & P Values \\
\hline Machiavellianism $\rightarrow$ Social support & .16 & .10 & 1.52 & .065 \\
Narcissism $\rightarrow$ Social support & -.09 & .19 & .48 & .314 \\
Psychopathy $\rightarrow$ Social support & .20 & .17 & 1.13 & .129 \\
Machiavellianism $\rightarrow$ Avoidance & .09 & .08 & 1.11 & .135 \\
Narcissism $\rightarrow$ Avoidance & .11 & .10 & 1.05 & .146 \\
Psychopathy $\rightarrow$ Avoidance & .35 & .11 & 3.15 & .001 \\
Control variables & & & .53 \\
Age $\rightarrow$ Social Media addiction & -.04 & .07 & .07 & .298 \\
Gender $\rightarrow$ Social Media addiction & .15 & & .014 \\
\hline
\end{tabular}

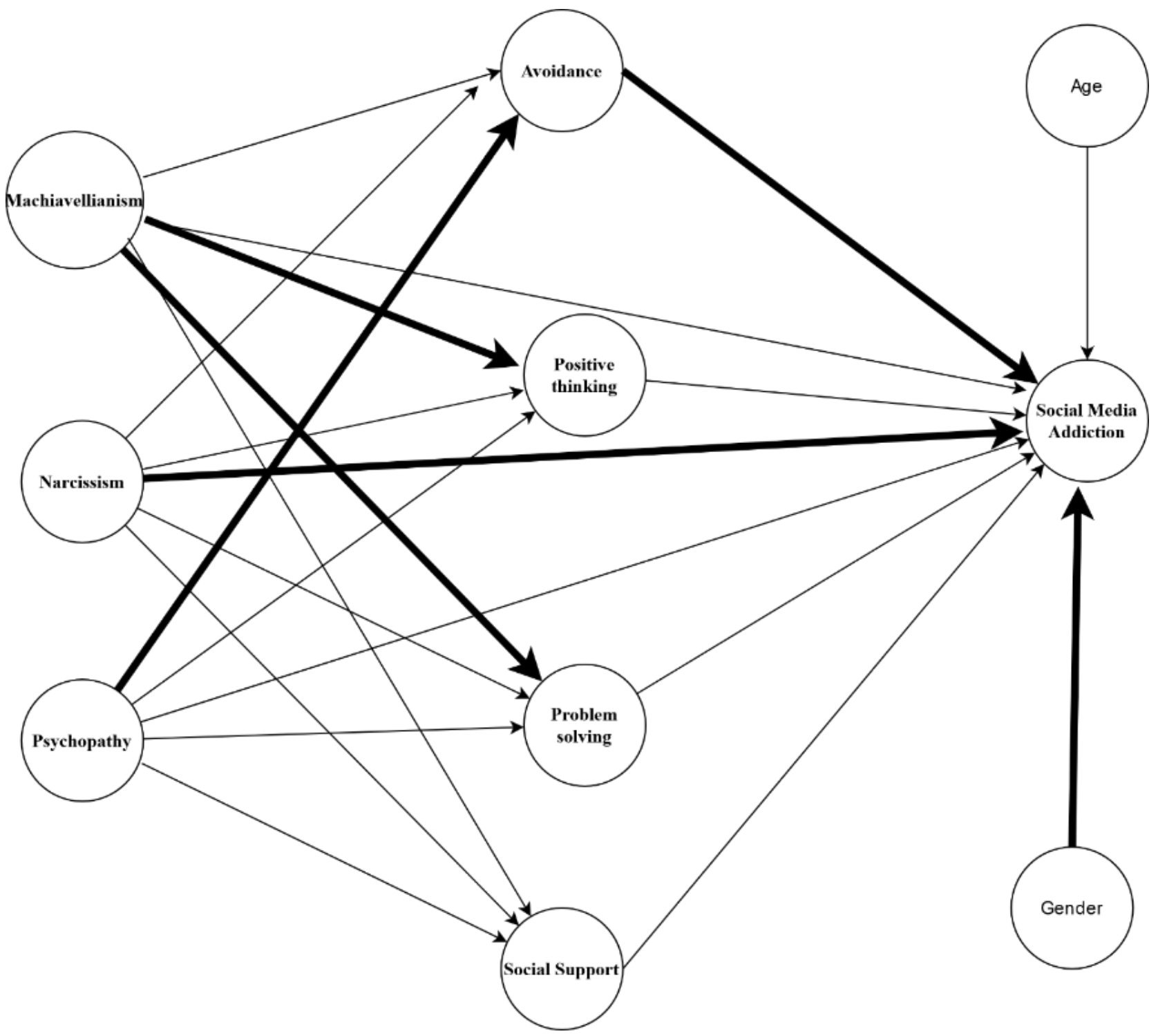

Figure 2. Results of analysis on the structural model. Note: Bold lines indicate the path coefficient was statistically significant, $p<.05$

\section{Mediating Effect}

As shown in Table 5, the specific indirect effect indicated that avoidance coping strategy is the statistical mediator for the impact of psychopathy on social media addiction, $p=.01$. Following the decision tree from 
Table 5. Results of Mediating Effects

\begin{tabular}{lcccc}
\hline & Beta & Std Error & T value & P Values* \\
\hline Mediating Effect & & & & \\
Machiavellianism $\rightarrow$ Social support $\rightarrow$ Social Media addiction & .02 & .02 & 1.16 & .123 \\
Narcissism $\rightarrow$ Social support $\rightarrow$ Social Media addiction & -.01 & .03 & .49 & .314 \\
Psychopathy $\rightarrow$ Social support $\rightarrow$ Social Media addiction & .03 & .03 & 1.08 & .139 \\
Machiavellianism $\rightarrow$ Problem solving $\rightarrow$ Social Media addiction & -.01 & .02 & .59 & .276 \\
Narcissism $\rightarrow$ Problem solving $\rightarrow$ Social Media addiction & -.01 & .01 & .13 & .448 \\
Psychopathy $\rightarrow$ Problem solving $\rightarrow$ Social Media addiction & .01 & .02 & .46 & .324 \\
Machiavellianism $\rightarrow$ Avoidance $\rightarrow$ Social Media addiction & .02 & .03 & .86 & .196 \\
Narcissism $\rightarrow$ Avoidance $\rightarrow$ Social Media addiction & .03 & .03 & .88 & .190 \\
Psychopathy $\rightarrow$ Avoidance $\rightarrow$ Social Media addiction & .09 & .04 & 2.35 & .010 \\
Machiavellianism $\rightarrow$ Positive thinking $\rightarrow$ Social Media addiction & .02 & .02 & 1.06 & .145 \\
Narcissism $\rightarrow$ Positive thinking $\rightarrow$ Social Media addiction & .00 & .02 & .22 & .414 \\
Psychopathy $\rightarrow$ Positive thinking $\rightarrow$ Social Media addiction & .02 & .02 & 1.04 & .150 \\
\hline
\end{tabular}

Zhao (2010), the results indicate an indirect-only mediation as the direct effect of psychopathy on social media addiction is not significant, $p=.448$.

\section{DISCUSSION}

Due to the high prevalence of social media addiction among the younger generation and its negative consequences, it is vital to find out the factors relevant to social media addiction among the younger generation so that strategies can be planned to reduce their social media addiction. This study adopted the personality-coping-outcome theory as a framework to examine the relationships between dark triad personality and coping strategies with social media addiction and whether coping strategies are statistical mediators for the effects of dark triad personality on social media addiction.

The results partially support the first hypothesis. Our results showed that not all dark triad personality types are associated with social media addiction. Only a significant positive association was found between narcissism and social media addiction. These results are consistent with a study that reported narcissism often spending excessive time in social media for selfie posting (Demircioğlu \& Köse, 2018). Fox et al. (2018) also reported that narcissism is more likely to participate in selfie-marketing on visual content-sharing apps. They are more likely to get admiration through selfie posting through social media.

However, we did not find a significant association between psychopathy trait and social media addiction reported by Chung (2019) and between Machiavellianism and social media addiction written, as Kircaburun et al. (2018) reported. Using the personality-coping-outcome theory as a framework, we argue that the associations between the three traits of dark triad personality with social media addiction can be indirectly mediated through specific coping strategies.

While examining the second hypothesis, which is whether coping strategies mediate the dark triad personality on social media addiction, it should be noted that all three Dark Triad Personality traits did not use social support coping strategies. These findings may indicate their common characterizes, which is poor social relationships. The results are consistent with other studies that revealed negative associations between dark triad personality and emotional intelligence (Baughman et al., 2012) and between dark triad personality and the preference of short-term relationships (Jonason \& Webster, 2012).

Besides, the results also show that the three types of dark triad personality adopted different coping strategies. These findings indicate that the differences among the three types of dark triad personality are also reflected in their coping strategies. As Furnam et al. (2013) reported, Machiavellian choose both soft and hard tactics, a psychopath is more likely to use hard tactics, and a narcissist is more likely to use soft manipulation tactics in a workplace. The results also found that Machiavellianism is associated with positive 
thinking and problem-solving coping strategies. Pathology is associated with avoidant coping strategies, and narcissism does not associate with any particular coping strategies. These findings seem to suggest that Machiavellian is more likely to tackle the problem directly in a flexible way. In contrast, a psychopath is more likely to avoid tackling issues directly, and a narcissist is more concentrated on themselves than the problems.

However, the findings that Machiavellianism is associated with positive thinking and problem-solving coping strategies seem to contradict Machiavellianism's definition. Positive thinking and problem-solving coping strategies are usually regarded as adaptive coping strategies (Ang \& Choi, 2005). Machiavellianism is an individual that is more morally suspect and likes to manipulate others in cold and selfish ways to achieve goals (Furnham et al., 2013; Ináncsi et al., 2016). The finding suggests a further revision of coping measurement is required, that whether to tackle problems with manipulating others to achieve goals can be regarded as positive thinking and problem solving or not.

The findings partially support the personality-coping-outcomes theory's predictions that coping strategies mediate personality's influence on the outcomes. The mediating analyses partially support the second hypothesis. The results showed avoidance coping strategy is a statistical mediator for the effects of pathology on social media. These findings are consistent with the suggestions from Demircioğlu and Köse (2018) and Jonason and Webster (2012) that psychopaths would not tackle their problems directly to avoid disciplinary actions, so they choose to express their reckless attitudes through social media and thus addict to social media.

However, inconsistent with the personality-coping-outcomes theory's predictions, the findings showed that narcissism is more likely to addict to social media without mediating coping strategies. These findings suggested that personality may directly affect the outcomes, not necessarily mediated by coping strategies. The findings did not show a significant association between Machiavellianism and social media addiction and the mediating effect of coping strategies. These findings are different from Kircaburn et al. (2018), who found that Machiavellianism excessively uses social media. A possible explanation is that as Machiavellianism is more likely to use positive thinking and problem-solving coping strategies, they may be more likely to use social media when they need to use social media to achieve goals. In other words, the use of social media is a way of coping, not an outcome.

\section{CONCLUSION}

In conclusion, the findings suggested that personality-coping-outcomes theory can only predict the associations between psychopaths and social media addiction. A complete theoretical framework is required to explain the relationships between the three types of dark triad personality and social media addiction. Besides, future studies may consider adopting a qualitative research to explore the coping strategies adopted by dark triad personality so that a scale can be developed to cover the possible coping strategy adopted by dark triad personality.

\section{LIMITATIONS OF THE STUDY}

The interpretation of the study needs to be cautious. As the study had only collected participants from a university, the findings may not generalize to other populations. Future studies may recruit samples from different people to examine the robustness of the results. Besides, as this study uses the cross-sectional design, the cause-effect explanation may also need to be cautious since there is a lack of time order. Future studies may consider using an experiment or longitudinal method to examine the cause-effect explanation.

Author contributions: All authors were involved in concept, design, collection of data, interpretation, writing, and critically revising the article. All authors approve final version of the article.

Funding: The authors received no financial support for the research and/or authorship of this article.

Declaration of interest: Authors declare no competing interest.

Data availability: Data generated or analysed during this study are available from the authors on request. 


\section{REFERENCES}

Afacan, O., \& Ozbek, N. (2019). Investigation of social media addiction of high school students. International Journal of Educational Methodology, 5(2), 235-245. https://doi.org/10.12973/ijem.5.2.235

Al Mamun, M. A., \& Griffiths, M. D. (2019). The association between Facebook addiction and depression: A pilot survey study among Bangladeshi students. Psychiatry Research, 271, 628-633. https://doi.org/10.1016/j.psychres.2018.12.039

Andreassen, C. S., Torsheim, T., Brunborg, G. S., \& Pallesen, S. (2012). Development of a Facebook addiction scale. Psychological Reports, 110(2), 501-517. https://doi.org/10.2466/02.09.18.PR0.110.2.501-517

Ang, C. C., \& Choi, J. N. (2005). Rethinking procrastination: Positive effects of" active" procrastination behavior on attitudes and performance. The Journal of Social Psychology, 145(3), 245-264. https://doi.org/10.3200/SOCP.145.3.245-264

Bányai, F., Zsila, Á., Király, O., Maraz, A., Elekes, Z., Griffiths, M. D., Andreassen, C. S., \& Demetrovics, Z. (2017). Problematic social media use: Results from a large-scale nationally representative adolescent sample. PLoS One, 12(1), e0169839. https://doi.org/10.1371/journal.pone.0169839

Baughman, H. M., Dearing, S., Giammarco, E., \& Vernon, P. A. (2012). Relationships between bullying behaviours and the Dark Triad: A study with adults. Personality and Individual Differences, 52(5), 571575. https://doi.org/10.1016/j.paid.2011.11.020

Baumstarck, K., Alessandrini, M., Hamidou, Z., Auquier, P., Leroy, T., \& Boyer, L. (2017). Assessment of coping: A new French four-factor structure of the brief COPE inventory. Health and Quality of Life Outcomes, 15(1), 8. https://doi.org/10.1186/s12955-016-0581-9

Benson, P. R. (2010). Coping, distress, and well-being in mothers of children with autism. Research in Autism Spectrum Disorders, 4(2), 217-228. https://doi.org/10.1016/j.rasd.2009.09.008

Book, A., Visser, B. A., \& Volk, A. A. (2015). Unpacking "evil": Claiming the core of the Dark Triad. Personality and Individual Differences, 73, 29-38. https://doi.org/10.1016/j.paid.2014.09.016

Carr, C. T., \& Hayes, R. A. (2015). Social media: Defining, developing, and divining. Atlantic Journal of Communication, 23(1), 46-65. https://doi.org/10.1080/15456870.2015.972282

Carver, C. S. (1997). You want to measure coping but your protocol' too long: Consider the brief cope. International Journal of Behavioral Medicine, 4(1), 92-100. https://doi.org/10.1207/s15327558ijbm0401_6

Chou, W.-P., Ko, C.-H., Kaufman, E. A., Crowell, S. E., Hsiao, R. C., Wang, P.-W., Lin, J.-J., \& Yen, C.-F. (2015). Association of stress coping strategies with Internet addiction in college students: The moderating

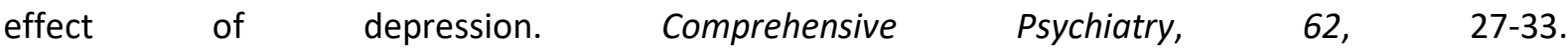
https://doi.org/10.1016/j.comppsych.2015.06.004

Chung, K. L., Morshidi, I., Yoong, L. C., \& Thian, K. N. (2019). The role of the dark tetrad and impulsivity in social media addiction: Findings from Malaysia. Personality and Individual Differences, 143, 62-67. https://doi.org/10.1016/j.paid.2019.02.016

Cohen, J. (1992). A power primer. Psychological Bulletin, 112(1), 155-159. https://doi.org/10.1037/00332909.112.1.155

Demircioğlu, Z. I., \& Köse, A. G. (2018). Effects of attachment styles, dark triad, rejection sensitivity, and relationship satisfaction on social media addiction: A mediated model. Current Psychology, 1-15. https://doi.org/10.1007/s12144-018-9956-x

Folkman, S. (2013). Stress: Appraisal and coping. In M. D. Gellman \& J. R. Turner (Eds.), Encyclopedia of Behavioral Medicine (pp. 1913-1915). Springer. https://doi.org/10.1007/978-1-4419-1005-9_215 
Fox, A. K., Bacile, T. J., Nakhata, C., \& Weible, A. (2018). Selfie-marketing: Exploring narcissism and selfconcept in visual user-generated content on social media. Journal of Consumer Marketing. https://doi.org/10.1108/JCM-03-2016-1752

Furnham, A., Richards, S. C., \& Paulhus, D. L. (2013). The Dark Triad of personality: A 10 year review. Social and Personality Psychology Compass, 7(3), 199-216. https://doi.org/10.1111/spc3.12018

Gallagher, D. J. (1996). Personality, coping, and objective outcomes: Extraversion, neuroticism, coping styles, and academic performance. Personality and Individual Differences, 21(3), 421-429. https://doi.org/10.1016/0191-8869(96)00085-2

Hadi, N. U., Abdullah, N., \& Sentosa, I. (2016). Making sense of mediating analysis: A marketing perspective. Review of Integrative Business \& Economics Research, 5(2), 62-76.

Hair Jr, J. F., Hult, G. T. M., Ringle, C., \& Sarstedt, M. (2016). A primer on partial least squares structural equation modeling (PLS-SEM). Sage Publications. https://doi.org/10.15358/9783800653614

Hare, R. D. (1998). Psychopathy, affect and behavior. In Psychopathy: Theory, research and implications for society (pp. 105-137). Springer. https://doi.org/10.1007/978-94-011-3965-6_6

Hawi, N. S., \& Samaha, M. (2017). Relationships among smartphone addiction, anxiety, and family relations. Behaviour \& Information Technology, 36(10), 1046-1052. https://doi.org/10.1080/0144929X.2017.1336254

Henseler, J., Ringle, C. M., \& Sarstedt, M. (2015). A new criterion for assessing discriminant validity in variance-based structural equation modeling. Journal of the Academy of Marketing Science, 43(1), 115135. https://doi.org/10.1007/s11747-014-0403-8

Hou, Y., Xiong, D., Jiang, T., Song, L., \& Wang, Q. (2019). Social media addiction: Its impact, mediation, and intervention. Cyberpsychology: Journal of Psychosocial Research on Cyberspace, 13(1). https://doi.org/10.5817/CP2019-1-4

Hyatt, C. S., Sleep, C. E., Lamkin, J., Maples-Keller, J. L., Sedikides, C., Campbell, W. K., \& Miller, J. D. (2018). Narcissism and self-esteem: A nomological network analysis. PloS One, 13(8), e0201088. https://doi.org/10.1371/journal.pone.0201088

Ináncsi, T., Láng, A., \& Bereczkei, T. (2016). A darker shade of love: Machiavellianism and positive assortative mating based on romantic ideals. Europe's Journal of Psychology, 12(1), 137. https://doi.org/10.5964/ejop.v12i1.1007

Jonason, P. K., \& Webster, G. D. (2012). A protean approach to social influence: Dark Triad personalities and social influence tactics. Personality and Individual Differences, 52(4), 521-526. https://doi.org/10.1016/j.paid.2011.11.023

Jones, D. N., \& Paulhus, D. L. (2014). Introducing the short dark triad (SD3) a brief measure of dark personality traits. Assessment, 21(1), 28-41. https://doi.org/Paulhus

Kircaburun, K., Jonason, P. K., \& Griffiths, M. D. (2018). The Dark Tetrad traits and problematic social media use: The mediating role of cyberbullying and cyberstalking. Personality and Individual Differences, 135, 264-269. https://doi.org/10.1016/j.paid.2018.07.034

Lazarus, R. S., \& Folkman, S. (1987). Transactional theory and research on emotions and coping. European Journal of Personality, 1(3), 141-169. https://doi.org/10.1002/per.2410010304

Mahamid, F. A., \& Berte, D. Z. (2019). Social media addiction in geopolitically at-risk youth. International Journal of Mental Health and Addiction, 17(1), 102-111. https://doi.org/10.1007/s11469-017-9870-8

Malaysian Communications and Multimedia Commission. (2018). Internet Users Survey 2018. https://www.mcmc.gov.my/skmmgovmy/media/General/pdf/Internet-Users-Survey-2018.pdf 
Malesza, M., \& Ostaszewski, P. (2016). Dark side of impulsivity-Associations between the Dark Triad, selfreport and behavioral measures of impulsivity. Personality and Individual Differences, 88, 197-201. https://doi.org/10.1016/j.paid.2015.09.016

Parker, J. D., \& Endler, N. S. (1992). Coping with coping assessment: A critical review. European Journal of Personality, 6(5), 321-344. https://doi.org/10.1002/per.2410060502

Paulhus, D. L., \& Williams, K. M. (2002). The dark triad of personality: Narcissism, machiavellianism, and psychopathy. Journal of Research in Personality, 36(6), 556-563. https://doi.org/10.1016/S00926566(02)00505-6

PrakashYadav, G., \& Rai, J. (2017). The Generation Z and their social media usage: A review and a research outline. Global Journal of Enterprise Information System, 9(2), 110-116. https://doi.org/10.18311/gjeis/2017/15748

Reinecke, L., Meier, A., Aufenanger, S., Beutel, M. E., Dreier, M., Quiring, O., Stark, B., Wölfling, K., \& Müller, K. W. (2018). Permanently online and permanently procrastinating? The mediating role of Internet use for the effects of trait procrastination on psychological health and well-being. New Media \& Society, 20(3), 862-880. https://doi.org/10.1177\%2F1461444816675437

Schou Andreassen, C., \& Pallesen, S. (2014). Social network site addiction-an overview. Current Pharmaceutical Design, 20(25), 4053-4061. https://doi.org/10.2174/13816128113199990616

Shaughnessy, J., Zechmeister, E., \& Zechmeister, J. (2015). Research methods in psychology (10th ed.). McGraw-Hill.

Skinner, E. A., Edge, K., Altman, J., \& Sherwood, H. (2003). Searching for the structure of coping: A review and critique of category systems for classifying ways of coping. Psychological Bulletin, 129(2), 216. https://doi.org/10.1037/0033-2909.129.2.216

Sriwilai, K., \& Charoensukmongkol, P. (2016). Face it, don't Facebook it: Impacts of social media addiction on mindfulness, coping strategies and the consequence on emotional exhaustion. Stress and Health, 32(4), 427-434. https://doi.org/10.1002/smi.2637

Suls, J., \& Fletcher, B. (1985). The relative efficacy of avoidant and nonavoidant coping strategies: A metaanalysis. Health Psychology, 4(3), 249-288. https://doi.org/10.1037/0278-6133.4.3.249

Thatcher, A., Wretschko, G., \& Fridjhon, P. (2008). Online flow experiences, problematic Internet use and Internet procrastination. Computers in Human Behavior, 24(5), 2236-2254. https://doi.org/10.1016/j.chb.2007.10.008

Zhao, X., Lynch Jr, J. G., \& Chen, Q. (2010). Reconsidering Baron and Kenny: Myths and truths about mediation analysis. Journal of Consumer Research, 37(2), 197-206. https://doi.org/10.1086/651257

Correspondence: Poh Chua Siah, Universiti Tunku Abdul Rahman, Kampar Campus, Malaysia.

E-mail: siahpc@utar.edu.my 